\title{
Los asentistas de galeras genoveses y la articulación naval de un impe- rio policéntrico (siglos XVI-XVII)*
}

\author{
Benoît Maréchaux ${ }^{1}$ \\ European University Institute, Florencia \\ b.marechaux@gmail.com
}

RESUMEN: Este artículo analiza la función que la escuadra de los asentistas de galeras genoveses desempeñó en la articulación de varios componentes territoriales del imperio hispánico entre la segunda mitad del siglo XVI y la primera mitad del siglo XVII. Mientras los estudios sobre la flota mediterránea de la Monarquía se han focalizado generalmente en el ejercicio de la guerra naval, este artículo muestra que, más allá de esta actividad, la escuadra de los genoveses fue clave para el transporte de soldados, metales preciosos, élites de gobierno e información entre la Península Ibérica y el norte de Italia. Este papel fue particularmente relevante durante la guerra de los Ochenta Años (1568-1648), cuando la situación en el Atlántico obligó a la Corona a utilizar el Mediterráneo como plataforma logística para la movilización de recursos hacia el norte de Europa. A través del análisis de la aportación de la escuadra hispano-genovesa a esta tarea de articulación

* Se han utilizado las abreviaciones siguientes: ADGG (Archivio Durazzo-Giustiniani di Genova), PAL RP (Pallavicini, Ramo Primogenito); ADM (Archivio Doria di Montaldeo, Génova); AGS (Archivo General de Simancas), CCG (Contadurías Generales), EST (Estado), GAL (Varios Galeras), GYM (Guerra y Marina); ASCG (Archivio Storico del Comune di Genova), MBS (Manoscritti Brignole Sale); ASG (Archivio di Stato di Genova), NA (Notai Antichi); ASR (Archivo Simón Ruiz, Medina del Campo); ASV (Archivio di Stato di Venezia), SDG (Senato, Dispacci Genova); MNM (Museo Naval de Madrid). Agradezco a Alejandra Franganillo Álvarez, Alejandro García Montón, Carlos Álvarez Nogal, Manuel Herrero Sánchez, Marina García Llorente y Yasmina Ben Yessef Garfia sus sugerencias y su atenta revisión del texto. El presente trabajo está vinculado al proyecto «Res Publica monárquica. La Monarquía Hispánica, una estructura imperial policéntrica de repúblicas urbanas [PGC2018095224-B-I00]» coordinado por Manuel Herrero Sánchez (Universidad Pablo de Olavide).

${ }^{1}$ ORCID iD: https://orcid.org/0000-0002-2722-1618.

Copyright: (C) 2020 CSIC. Este es un artículo de acceso abierto distribuido bajo los términos de una licencia de uso y distribución Creative Commons Reconocimiento 4.0 Internacional (CC-BY 4.0) 
naval, este trabajo pretende contribuir a un mayor entendimiento de las instituciones de tipo transnacional que fomentaban la conexión y la circulación entre los diferentes componentes de un imperio policéntrico.

PALABRAS ClAVES: asentistas de galeras; Génova; historia naval; Mediterráneo; Monarquía Hispánica; transporte de la plata.

Genoese galley contractors and shipping connections in a polycentric empire (sixteenth and seventeenth centuries)

ABSTRACT: This article analyses the role played by the squadron of Genoese galley contractors in facilitating connections between territories belonging to the Spanish empire between the second half of the sixteenth century and the first half of the seventeenth. While studies on the Spanish monarchy's Mediterranean fleet have generally focused on war, this article shows how the Genoese squadron was also decisive in ensuring the transport of soldiers, precious metal, government elites and information between the Iberian Peninsula and northern Italy. It played a particularly important role during the Eighty Years' War (1568-1648), when the situation in the Atlantic forced the Crown to use the Mediterranean as a logistical platform for mobilizing resources towards Northern Europe. By investigating the contribution of the Spanish-Genoese squadron in this context, this study casts some light on the transnational institutions that fostered connections and circulation between the different territorial components of a polycentric empire.

KEY WORDS: Galley contractors; Genoa; Mediterranean studies; Naval History; Silver transportation; Spanish Monarchy.

CÓMO CITAR ESTE ARTÍCULO/CITATION: Maréchaux, Benoît, «Los asentistas de galeras genoveses y la articulación naval de un imperio policéntrico (siglos XVI-XVII)», Hispania, 80/264 (Madrid, 2020): 47-77. https://doi.org/10.3989/hispania.2020.002.

\section{INTRODUCCIÓN}

Recientemente, el análisis de la Monarquía Hispánica como entidad global ha sido objeto de reconsideraciones relevantes. Después de un período marcado por la irrupción del concepto de composite monarchies, que llevó a enfatizar la fragmentación del agregado imperial, los investigadores han empezado a preguntarse sobre los mecanismos que contribuyeron a enlazar los diferentes espacios políticos controlados por los Habsburgo ${ }^{2}$. En vez de poner el acento sobre las relaciones verticales Corte-periferias, consideradas insuficientes como para dar cuenta de las dinámicas de un imperio policéntrico, los estudiosos se han interesado cada vez más por los agentes y las instituciones transnacionales que

${ }^{2}$ ELLIOTT, 137/1 (Oxford, 1992): 48-71. CARDIM, HERZOG, RUIZ IBÁÑEZ y SABATINI, 2012.

Hispania, 2020, vol. LXXX, n. ${ }^{\circ}$ 264, enero-abril, págs. 47-77, ISSN: 0018-2141, e-ISSN: 1988-8368

https://doi.org/10.3989/hispania.2020.002 
favorecieron el desarrollo de relaciones interterritoriales y pudieron dotar el conjunto de una mayor cohesión. Al romper con la habitual dicotomía instituciones/ redes interpersonales, se ha procedido a estudiar a las redes mercantiles, a los entramados aristocráticos, burocráticos y militares, o a las congregaciones religiosas como vectores transnacionales que, con más o menos éxito, ayudaron a conectar las diferentes partes del aglomerado imperial ${ }^{3}$. De ahí, también, el interés creciente por planteamientos de historia global, y en especial por la circulación de personas, bienes, información y conocimientos entre los dispersos centros (políticos, portuarios, culturales...) de tan compleja estructura política ${ }^{4}$.

Desde esta perspectiva, resulta muy sugerente preguntarse sobre la función que las instituciones navales jugaron para la articulación global del imperio. Como instrumento de protección militar y medio de comunicación marítima, las flotas armadas eran herramientas claves para conectar territorios distantes en un contexto de alta inseguridad. Más allá de su papel en las batallas navales, dichas flotas resultaban esenciales por las travesías periódicas que realizaban entre las posesiones de la Monarquía. De ellas dependía el transporte de hombres y recursos necesarios para el mantenimiento del imperio. Sin la Flota de Indias, la Armada de Barlovento o el Galeón de Manila, la Corona nunca hubiera podido llegar a conectar las «cuatro partes del mundo» ${ }^{5}$. Aunque no suele ser asociado con la primera globalización hispánica, el Mediterráneo nunca dejó de ser un espacio muy estratégico para la Monarquía y constituye también un excelente observatorio para analizar estas dinámicas. La fragmentación de las posesiones de los Habsburgo entre las penínsulas ibérica e italiana obstaculizaba la comunicación y, por lo tanto, la articulación de los dominios hispánicos dispersos en el mundo mediterráneo ${ }^{6}$. De ahí la necesidad que la Corona tuvo de poner en marcha unas instituciones navales transnacionales capaces de establecer una conexión marítima entre sus territorios. Nadie explicó mejor el problema que Richelieu, quien, de hecho, comparó las galeras mediterráneas con los navíos del Atlántico en su actividad de articulación intra-imperial:

La séparation des Etats qui forment le corps de la monarchie espagnole en rend la conservation si difficile que, pour leur donner quelque liaison, l'unique moyen

3 STUDNICKI-GIZBERT, 2007. CRESPO SOLANA, 2009. YUN CASALILLA, 2009; 2019. MALDAVSKY, 2012. GRAFE, 2014. ANTUNES Y POLÓNIA, 2016. HERRERO SÁNCHEZ, LXXVI/253 (Madrid, 2016): 445-472. HERRERO SÁNCHEZ Y KAPS, 2017.

${ }^{4}$ GRUZINSKI, 2004. SUBRAHMANYAM, CXII/5 (Chicago, 2007): 1359-1385. BRENDECKE, 2012. ARAM y YUN CASALILLA, 2014. GAUDIN y VALENZUELA MÁRQUEZ, 25 (Toulouse, 2015): 13-24.

${ }^{5}$ La expresión es de GRUZINSKI, 2004. CHAUNU y CHAUNU, 1955-1960. SERRANO MANGAS, 1989. GARCÍA-BAQUERO GONZÁLEZ, 1992. LANG, 1998. BONIALIAN, 2012. BERNABÉU ALBERT, 2013. GIRÁLDEZ, 2015.

${ }^{6}$ Una síntesis del problema en PACINI, 2013. 
qu'ait l'Espagne est l'entretien de grand nombre de vaisseaux en l'Océan et de galères en la Méditerranée, qui, par leur trajet continuel, réunissent en quelque façon les membres à leur chef, portent et rapportent les choses nécessaires à leur subsistance, les ordres de ce qui doit être entrepris, les chefs pour commander, les soldats pour exécuter, l'argent qui est non seulement le nerf de la guerre, mais aussi la graisse de la paix. Dont il s'ensuit que, si on empêche la liberté de tels trajets, ses Etats, qui ne peuvent subsister d'eux-mêmes, ne sauraient éviter la confusion, la faiblesse et toutes les désolations dont Dieu menace les Royaumes divisés. Or, comme la côte du Ponant de ce Royaume sépare l'Espagne de tous les Etats possédés en Italie par leur roi, ainsi il semble que la providence de Dieu [...] a voulu que la situation de la France séparât les Etats d'Espagne pour les affaiblir en les divisant ${ }^{7}$.

Para Richelieu, las galeras constituían el único medio que la Monarquía de los Austrias tenía para conectar sus territorios mediterráneos y conservar el conjunto de sus estados. Sencillamente, el imperio no se podía mantener sin su circulación ${ }^{8}$. El ministro francés precisó las funciones que estas embarcaciones asumían para la articulación de la potencia rival. Señaló concretamente el transporte de bienes, de información, de las élites de gobierno, de la infantería y de dinero. Dicho listado coincide perfectamente con las actividades de comunicación marítima que las galeras de los asentistas genoveses desempeñaron continuamente a través del Mediterráneo a lo largo de los siglos XVI y XVII.

Desde su nacimiento en 1528, la escuadra liderada por los Doria se había especializado en la movilización de recursos entre los diferentes territorios del sistema imperial hispánico. Ya bajo Carlos V, y tal y como señaló Carande, «el servicio de galeras en el Mediterráneo, imprescindible para asegurar las comunicaciones y los transportes entre el levante español, el occidente italiano y las plazas del norte de África, lo realiza, en su mayor parte, Andrea Doria» ${ }^{9}$. Las galeras genovesas jugaron un papel aún más determinante a partir de la década de 1570, cuando, a raíz de la sublevación holandesa (1566), el cierre de la ruta atlántica obligó a la Corona a pasar por el Mediterráneo para enviar hombres y recursos hacia Alemania y Flandes ${ }^{10}$. En estas circunstancias, la escuadra de los asentistas genoveses fue clave para conectar la Península Ibérica con Génova, y desde allí, Lombardía y el «camino español». Como lo atestiguan los diarios de algunos patricios genoveses o la correspondencia de los cónsules venecianos en Génova, las galeras de los asentistas, que realizaban idas y

\footnotetext{
7 RICHELIEU, 2011: 287-288. Sobre la visión naval de Richelieu y su testamento político, véanse HILDESHEIMER, 2004: 502-518. BERBOUCHE, 2010: 21-22.

${ }^{8}$ Una idea que compartía también Campanella que subrayó que la navegación era la única forma para unir «miembros muy alejados entre sí», antes de asegurar que «deshechos estos vínculos caerá todo el cuerpo de esta monarquía». Citado en HERRERO SÁNCHEZ, LXV/219 (Madrid, 2005b): 117.

9 CARANDE, 1990, vol. II: 25.

${ }^{10}$ PARKER, 2006.
} 
venidas continuas entre España e Italia, marcaban el ritmo de los flujos de dinero, de hombres y de información a través del Mediterráneo Occidental ${ }^{11}$. Esta actividad era bien conocida por los ministros de la Corona. Como señalara el Marqués de Villafranca en una sesión del Consejo de Guerra de 1611, en la que se discutía una propuesta del contratista Ambrosio Spínola (hijo de Francesco), quién se había ofrecido a tomar más galeras en asiento:

... es tanto de estimar, que no se deve dilatar este provecho, ni por este asiento, escusar el crecimiento de mas galeras, pues son el puente, que Vuestra Majestad tiene en reynos tan divididos, y el unico remedio para unirlos en un cuerpo i acudir al socorro dellos con unas mesmas fuerzas a un tiempo (sic) ${ }^{12}$.

Pese a ello, la historiografía naval ha pasado habitualmente por alto estas actividades y ha focalizado su atención en la función bélica de las galeras del rey, especialmente en la lucha contra el Imperio Otomano ${ }^{13}$. Más recientemente, bajo la influencia de una renovación de los estudios de historia nava ${ }^{14}$, el debate se ha ampliado y algunos estudiosos se han interesado específicamente por estas funciones logísticas de las galeras. De este modo, se han analizado, por ejemplo, los fundamentos geopolíticos de la «rotta spagnola» en el Mediterráneo ${ }^{15}$, y se ha examinado el caso del papel desempeñado por la escuadra española para aprovisionar los presidios del norte de África a principios del siglo XVII ${ }^{16}$. Este trabajo propone avanzar aún más sobre este problema de la articulación intra-imperial analizando en detalle las actividades de transporte realizadas por los asentistas genoveses para conectar las penínsulas italiana y española. Por un lado, contribuye a explicar por qué, después de la década de 1570 y el fin de los grandes enfrentamientos hispano-otomanos, la Corona seguía teniendo buenos motivos para contratar los servicios de asentistas de galeras genoveses ${ }^{17}$. Por otro lado, se muestra cómo, de forma aparentemente paradójica, el aumento de la conflictividad en el Atlántico creó una demanda de servicios navales en el Mediterráneo. A una escala más amplia, este caso de estudio puede ayudar a entender mejor cómo la construcción imperial se apoyó en instituciones transnacionales que contribuyeron enormemente a tejer relaciones interterritoriales a

${ }^{11}$ PALlaViCINO, 1975. ASCG, MBS, ms. 109 D4 (1600-1610). ASV, SDG, filze 3-8 (1613-1647).

12 Consulta del Consejo de Guerra, AGS, GYM, leg. 744, 26/04/1611.

13 GUILMARTIN, 1974. BRAUDEL, 1990. GARCIA HERNÁN, 1995. BARBERO, 2012. WILLIAMS, 2014.

${ }^{14}$ GLETE, 2000. LO BASSO, 2003.

15 PACINI, 2013.

16 LOMAS CORTÉS, 2011.

${ }_{17}$ Sobre la importancia militar que seguían teniendo las flotas de galeras, véase WILLIAMS, 2003.

Hispania, 2020, vol. LXXX, n. ${ }^{\circ}$ 264, enero-abril, págs. 47-77, ISSN: 0018-2141, e-ISSN: 1988-8368 https://doi.org/10.3989/hispania.2020.002 
escala global. Después de presentar la escuadra de los asentistas, se analizan las cuatro funciones principales que esta formación ejercía para la articulación del imperio entre la segunda mitad del siglo XVI y la primera mitad del XVII: el transporte de los soldados, de la plata, de las élites y de la información.

\section{LA ESCUADRA DE LOS ASENTISTAS DE GALERAS GENOVESES}

Lejos de corresponderse con el modelo que asocia la revolución militar a la centralización de la administración y al desarrollo de las flotas estatales, el imperio de Carlos V creó en el Mediterráneo un sistema naval policéntrico basado en la contratación de emprendedores privados ${ }^{18}$. A pesar de no ser sujetos de la Corona, los genoveses jugaron un papel relevante en este dispositivo y contribuyeron enormemente al desarrollo naval de una Monarquía que apenas contaba con una flota permanente en el Mediterráneo a principios del siglo XVI ${ }^{19}$. El acuerdo particular de condotta alcanzado por Andrea Doria con Carlos $\mathrm{V}$ en 1528 supuso un salto cuantitativo y cualitativo notable para las fuerzas navales del imperio ${ }^{20}$. Las 12 galeras del armador genovés, que pasaron a ser 15 en 1530 y 20 en 1539, se convirtieron en el núcleo de la flota hispánica en el Mediterráneo ${ }^{21}$. A esas unidades se añadieron además las de Agostino Grimaldi, Visconte Cicala y Antonio Doria, quienes, desde Mónaco, Nápoles o Sicilia, y con sus propias escuadras, operaron con entre 7 y 10 galeras hasta el inicio del reinado de Felipe $\mathrm{II}^{22}$. Entre las décadas de 1530 y 1550 , los genoveses sirvieron, de este modo, con aproximadamente entre 22 y 30 galeras en una flota que no debía superar las 40 unidades en tiempos ordinarios $^{23}$. El poderío naval de Carlos $\mathrm{V}$ en el Mediterráneo era eminentemente genovés, algo que no se ha valorado lo suficiente hasta la fecha. Probablemente por primera vez, un Estado desarrolló una escuadra de galeras permanente basada en el uso de barcos privados gestionados por emprendedores navales. A pesar de que este método se ha considerado generalmente como una forma débil de administración militar, el caso de los genoveses es prueba de gran resiliencia en el tiempo.

18 Sobre la revolución militar en el ámbito naval: THOMPSON, 1976. PARKER, 1988. RODGER, 13/2 (Londres, 2011): 119-128. PARROTT, 2012. Una síntesis sobre la flota hispánica: BUNES IBARRA, V (Madrid, 2006): 77-99.

19 MIRA CABALLOS, XVIII/68 (Madrid, 2000): 35-54. THOMPSON, 24 (Barcelona, 2006): 95-124. LADERO QUESADA, 2010.

${ }^{20}$ Sobre la incorporación de Andrea Doria, véase PACINI, 1999.

${ }^{21}$ Andrea Doria a Carlos V, AGS, EST, leg. 1362, doc. 115-117, 04/06/1529. Copias de asientos de galeras, MNM, Colección Sanz de Barutell, n. ${ }^{\circ} 396$, doc. 1, 18/03/1530, y doc. 20, 31/05/1539.

22 SAVELLI, 1992. LERCARI, 1996. SIRAGO, 2001; 2018. FENICIA, 2003. LOBASSO, 2007.

${ }^{23}$ Para el número de galeras de la flota, véase THOMPSON, 24 (Barcelona, 2006): 97-98. 
La escuadra de Andrea Doria — que se convertiría más adelante en la de Génova - se caracterizaba por su fuerte componente transnacional. La formación naval se basaba en contratos públicos que formalizaban una relación de intercambio entre, por un lado, la Monarquía Hispánica, y, por otro lado, emprendedores navales italianos que no eran sujetos del rey. Contratar a extranjeros de este perfil permitía a la Corona atraer un capital humano cualificado y contar con fuerzas navales de gran valor estratégico ${ }^{24}$. Por su parte, los nobles genoveses tenían interés en servir a otra potencia por los beneficios económicos y las oportunidades sociopolíticas brindadas por este tipo de inversiones. El resultado de dicha colaboración era la formación de una escuadra híbrida financiada con fondos de las arcas castellanas, pero con base naval y centro de gestión localizados en Génova. La función de la escuadra consistía principalmente en controlar el espacio septentrional del Mediterráneo Occidental y en establecer una línea de comunicación entre España e Italia.

Estas características explican la poca fortuna historiográfica de la escuadra hispano-genovesa. Al no ser una formación «española», «italiana», o «genovesa», propiamente dicha, no ha suscitado el interés de estudiosos que tradicionalmente han analizado el problema de las flotas desde un planteamiento localista, regionalista o nacionalista. La dispersión de las fuentes empeoró esta tendencia. Solo recientemente se ha empezado a investigar la cuestión y a reconocer su interés historiográfico ${ }^{25}$. Como indicara el coordinador de un monográfico sobre las relaciones hispano-genovesas aparecido en 2005 en la revista Hispania, era incomprensible que, «en concordancia con la importancia de Génova para el buen funcionamiento del sistema de comunicaciones entre los dispersos territorios de la Monarquía ${ }^{26}$, todavía no se hubiese realizado un trabajo sobre la cuestión. Dicha observación resulta aún más acertada si consideramos el mayor interés generado por la escuadra de la República de Génova ${ }^{27}$, cuyo volumen fue mucho menor al alcanzado por la de los asentistas durante los siglos XVI y XVII.

A principios del reinado de Felipe II, la formación de los asentistas genoveses experimentó, en efecto, un importante desarrollo ${ }^{28}$. De la escuadra de Andrea Doria, se pasó en unos quince años (1555-1570) a lo que se podría denominar la escuadra «compuesta» de los particulares de Génova. Bendinelli Sauli (1555), Stefano de Mari (1560), Marco Centurione (1561-1562), Nicolò y Agostino

${ }^{24}$ El Imperio Otomano procedió de una forma parecida con los hermanos Barbarroja. Su incorporación le permitió acceder a determinadas bases navales como Argel, además de obtener la colaboración de los corsarios berberiscos cuyo papel fue esencial para la articulación naval otomana. GÜRKAN, 1/2 (Leiden, 2010): 125-163.

${ }^{25}$ LO BASSO, 2003; 2007; 2011. Véase también CARPENTIER Y PRIOTTI, 2011.

${ }^{26}$ HERRERO SÁNCHEZ, LXV/219 (Madrid, 2005a): 19.

${ }^{27}$ KIRK, 2005.

${ }^{28}$ Estos párrafos sintetizan muy brevemente argumentos de $\mathrm{mi}$ tesis doctoral (MARÉCHAUX, 2017: 59-74). 
Lomellini (1566) y Giorgio Grimaldi (1566) pusieron sus galeras al servicio del soberano. De forma más excepcional, Marcello Doria gestionó algunas del rey $(1575-1581)^{29}$. La escuadra era el conjunto, todavía poco definido, de las galeras armadas por genoveses y que servían generalmente bajo el mando de los Doria. Entre 1566 y 1580, la formación contó siempre con un mínimo de 24 galeras. El contraste con las fuerzas de la república genovesa — que se habían presentado con tres unidades en Lepanto- es tan llamativo como significativo ${ }^{30}$. Los contratistas genoveses conformaban una de las escuadras más importantes del Mediterráneo, aunque el desarrollo naval impulsado por Felipe II (por ejemplo, en Nápoles) redimensionó su contribución relativa dentro de la flota.

A partir de la década de 1580 , la escuadra se convirtió en una formación más unitaria, a la vez que se asistió a una reafirmación del poder regio mediante la adquisición de diez galeras de los Doria que pasaron a ser gestionadas por Cosimo Centurione, Agabito Grillo y Gio. Antonio de Marini. Por otro lado, los efectivos de la escuadra disminuyeron. La veintena de galeras que operaba en Génova en 1585 se redujo a unas 14-15 al final del reinado de Felipe II. El creciente retraso de los pagos por parte de la Corona dificultó el servicio de varios asentistas, y la calidad de la escuadra empeoró. La formación naval estaba entonces dominada por los grandes linajes de la oligarquía genovesa (los Doria, Centurione, Spinola...) que, al introducir elevadas barreras de entrada, controlaban el negocio de las galeras de forma casi patrimonial. Este componente oligárquico fue otra característica muy importante de la escuadra a lo largo de los casi dos siglos de su existencia.

El valimiento del duque de Lerma introdujo un cambio de prioridades en la política exterior de la Monarquía. Se puso de nuevo el foco en la conservación de los dominios italianos y en la lucha contra el Imperio Otomano, lo que llevó a los dirigentes a convenir sobre la necesidad de reformar y consolidar la flota del Mediterráneo ${ }^{31}$. La Corona reforzó la financiación de la escuadra genovesa, renegoció sus contratos, añadió nuevas galeras, incrementó el número de remeros en cada una de ellas e incorporó nuevos asentistas. A principios de la década de 1610, la formación contaba con 18 galeras y empleaba a alrededor de 4.000 individuos ${ }^{32}$. Esta evolución contrastó con la de otras escuadras, y particularmente con la de España que, en 1606, contaba tan solo con siete galeras ${ }^{33}$.

La escuadra dirigida por los Doria empezó a experimentar las señales de una progresiva crisis a partir de la década siguiente. Con la llegada al poder de

${ }^{29}$ La situación de Sauli y de Mari era ambigua. Tenían en principio su base en Nápoles, pero servían a menudo con las galeras de los genoveses.

${ }^{30}$ BARBERO, 2012.

31 GARCÍA GARCÍA, 1996. MARÉCHAUX, 2012.

32 AGS, GAL, leg. 92-93.

33 THOMPSON, 1976: 301.

Hispania, 2020, vol. LXXX, n. ${ }^{\circ}$ 264, enero-abril, págs. 47-77, ISSN: 0018-2141, e-ISSN: 1988-8368 https://doi.org/10.3989/hispania.2020.002 
Olivares, los esfuerzos de la Corona se dirigieron cada vez más hacia el norte de Europa ${ }^{34}$. El gobierno planteó a partir de 1623 una reforma de la escuadra, pero los asentistas se opusieron a ella al sostener que lo urgente era resolver el problema causado por las crecientes cantidades de dinero que la Corona les pagaba en vellón ${ }^{35}$. La escuadra perdió gran parte de su consistencia y efectividad a lo largo de los años siguientes y, en estas circunstancias, el estallido del conflicto con Francia en 1635 supuso una prueba de fuego de la que la formación se resintió duramente. Solo ocho galeras estaban operativas en $1640 \mathrm{y}$, después de la operación de Tarragona (1642), la escuadra se quedó casi sin efectivos. Se procuró restaurar su estado construyendo nuevas galeras y dando ciertas garantías a los asentistas, pero sin éxito. A lo largo de la década de 1640 , fallecieron, además, cuatro de los cinco contratistas que habían constituido la columna vertebral de la escuadra entre 1625 y 1640 (Silvestro Grimaldi, Battista Serra, Bartolomeo Spinola y Carlo Doria). Como en el sector de las finanzas, la extinción de los principales asentistas supuso el fin de un período, aunque eso no impidió que, si bien con pocos efectivos, la escuadra siguiese operando hasta principios del siglo XVIII ${ }^{36}$.

\section{LA TRANSFERENCIA DE SOLDADOS Y DE MATERIAL MILITAR}

Para sustentar Milán, su principal plaza de armas en el norte de Italia, y para hacer frente a la rebelión flamenca, el Imperio Habsburgo necesitaba transferir cada año a miles de soldados destinados a combatir fuera de su región de origen. Como consecuencia, la Corona tuvo que construir un sistema global de expatriación militar que permitiese el desplazamiento masivo de reclutas desde España y el reino de Nápoles hacia Lombardía y, desde allí, hasta el norte de Europa $^{37}$. Los efectivos movilizados eran relevantes. Entre 1567 y 1574, al menos 43.000 soldados españoles fueron trasladados a Italia o Flandes y el ritmo siguió siendo elevado a lo largo de las siguientes décadas ${ }^{38}$. Para fomentar la circulación de sus soldados sin pasar por el Atlántico, la Corona tuvo que desarrollar el conocido «camino español» ${ }^{39}$, pero también, una ruta marítima que conectara España y el reino de Nápoles con las costas de Liguria. Según

\footnotetext{
34 THOMPSON, 1990: 251-253. ELLIOTT, 2009: 83-113 у 238-281.

35 AGS, GYM, leg. 912.

36 Sobre el ocaso de una generación de banqueros genoveses en esta misma década, véase ÁLVAREZ NOGAL, LXV/219 (Madrid, 2005b): 84-88. Sobre los últimos años de la escuadra: LO BASSO, 2007: 425-428.

37 PARKER, 2006. RODRÍGUEZ HERNÁNDEZ, 2007. MAFFI, 2007. MARTÍNEZ RUIZ, 2008.

${ }^{38}$ MAFFI, 2007: 129.

39 PARKER, 2006.
}

Hispania, 2020, vol. LXXX, n. ${ }^{\circ}$ 264, enero-abril, págs. 47-77, ISSN: 0018-2141, e-ISSN: 1988-8368 https://doi.org/10.3989/hispania.2020.002 
algunas estimaciones, al menos 200.000 soldados fueron embarcados o desembarcados en la revière de Liguria entre 1567 y $1650^{40}$.

TABLA 1. El transporte de infantería en la escuadra de Génova (1580-1598, ejemplos) ${ }^{41}$

\begin{tabular}{|c|c|c|c|c|}
\hline Año & Travesía & Efectivos & N. ${ }^{\mathbf{g a l}}$ & Observaciones \\
\hline 1580 & Liguria - España & 4.600 & & $\begin{array}{c}\text { Soldados españoles } \\
\text { de vuelta de Flandes }\end{array}$ \\
\hline 1582 & Nápoles - Génova & 9 compañías & 11 & \\
\hline 1585 & España - Liguria & 2.800 & 19 & \\
\hline 1586 & España - Liguria & 17 compañías & & Soldados destinados a Flandes \\
\hline 1587 & España - Liguria & 6.000 & 16 & Junto con la escuadra de Nápoles \\
\hline 1589 & España - Liguria & $5.000-6.000$ & 14 & Junto con la escuadra de Nápoles \\
\hline 1590 & Liguria - España & $5.000-6.000$ & 16 & $\begin{array}{c}\text { Junto con las escuadras de } \\
\text { España y de Nápoles }\end{array}$ \\
\hline 1591 & Nápoles - Liguria & 7 compañías & & $\begin{array}{c}\text { Soldados italianos } \\
\text { destinados a Flandes }\end{array}$ \\
\hline 1593 & España - Liguria & 7.000 & & $\begin{array}{c}\text { Junto con la escuadra } \\
\text { de Nápoles. Flandes }\end{array}$ \\
\hline 1595 & España - Liguria & 3.000 & & Soldados destinados a Flandes \\
\hline 1596 & España - Liguria & 9 compañías & 8 & \\
\hline 1597 & Liguria - España & 2.000 & 18 & \\
\hline 1597 & España - Liguria & 1.500 & 17 & \\
\hline 1598 & Nápoles - Liguria & 1.000 & & \\
\hline
\end{tabular}

Fuentes: AGS, EST, leg. 1413-1429 y leg. 1931. VARGAS HIDALGO, 2002: 1053-1564. MAFFI, 2007.

Este esfuerzo logístico fue asumido por los buques de la flota hispánica en el Mediterráneo y, principalmente, por las galeras de los genoveses ${ }^{42}$. Casi cada año, se solicitaba a la escuadra que trasladara numerosos efectivos de infantería a través del Mediterráneo. Lo más habitual era que los asentistas recogiesen a

\footnotetext{
${ }^{40}$ MAFFI, 2007: 144-146.

${ }^{41}$ El número de galeras indicado se refiere a las unidades de los asentistas genoveses.

42 Debido a la crisis de las escuadras de galeras, el método cambió en la segunda mitad del siglo XVII. Véase RODRÍGUEZ HERNÁNDEZ, 5/10 (Zaragoza, 2016): 39-42.
} 
los soldados en las costas españolas y que los llevasen a Liguria. La documentación indica a menudo Flandes como destino de los tercios embarcados. En otras ocasiones señala simplemente a Milán, aunque es probable que, desde allí, una parte de las tropas emprendiese el «camino español». Las galeras contribuían de este modo a la movilización mediterránea de los recursos humanos destinados al norte de Europa. Las galeras se utilizaban a su vez para repatriar a los veteranos que habían luchado en el frente flamenco. Con menor frecuencia, trasladaban también soldados entre Nápoles y Liguria. Del examen de estas actividades durante dos décadas (1580-1598), se desprende que los efectivos transportados alcanzaban cifras de gran magnitud. La tabla 1, que presenta ejemplos de travesías para las cuales disponemos de algunas cifras, lo atestigua.

Estas operaciones, que solían durar semanas e incluso meses, requerían planificación. Se insertaban dentro de una cadena logística más amplia, por lo que era importante respetar los tiempos previstos. Se procuraba evitar que la infantería realizase el camino español en invierno, o que el ejército de Flandes estuviese en apuros al no disponer de los reclutas a tiempo. El problema era principalmente de coordinación. Mover a miles de soldados de un punto a otro del Mediterráneo requería que muchos actores (el gobierno central, los Doria, los asentistas, los capitanes de galeras, los comisarios de la Corona, las autoridades locales, los capitanes de infantería...) se pusieran de acuerdo. Una vez que las tropas estaban embarcadas, se debía lidiar con su gestión a bordo. La concentración de soldados mal pagados en las galeras era propicia para el amotinamiento y los altercados. Por ejemplo, en 1574, mientras sus unidades estaban en Cagliari y a punto de salir para Génova, Marcello Doria se enfrentó a una pelea general entre el tercio de Lope de Figueroa y los marineros genoveses. De la confrontación resultaron varios muertos y heridos ${ }^{43}$.

En marzo de 1587, Felipe II comunicó a Gian Andrea Doria que la Corona estaba planificando la transferencia de 6.000 soldados españoles a Italia ${ }^{44}$. Debido al número elevado de tropas por llevar, las escuadras de Génova y de Nápoles realizarían la expedición de forma conjunta. Las galeras debían prepararse para llegar a las costas de Cataluña a mediados de abril. «Vos lo ordenad de manera que no haya falta ni dilación en quanto al tiempo (sic)», advirtió Felipe II a su Capitán General de la Mar. El objetivo era que la infantería llegase cuanto antes a Italia, y que las galeras se liberasen para poder «andar limpiando la mar». En realidad, las operaciones se retrasaron. Las galeras de los genoveses llegaron el 18 de junio a Barcelona bajo el mando de Agabito Grillo. Allí, el asentista recibió la orden de recoger a las tropas que estaban convergiendo hacia los puertos de embarque. Grillo pasó primero por Cartagena para recoger a siete compañías; a continuación, se dirigió hacia

\footnotetext{
${ }^{43}$ Juan de Idiáquez a Felipe II, AGS, EST, leg. 1404, doc. 34, 07/06/1574.

${ }^{44}$ Para este párrafo, véase AGS, EST, leg. 1419. VARGAS HIDALGO, 2002: 1204-1212.
} 
Denia para embarcar a los reclutas del reino de Valencia; mientras tanto, otras unidades, que se debían embarcar en Tortosa, bajaron por el Ebro. Ya que no se sabía el tiempo que las galeras napolitanas tardarían en llegar, y que algunas de las genovesas se quedaron para transportar plata de los banqueros de Madrid, las restantes se cargaron al máximo de sus posibilidades. La media fue superior a 150 soldados por galera, algo que Gian Andrea Doria consideró arriesgado ${ }^{45}$. Con estos soldados solían viajar sus mujeres y niños, lo que incrementaba los efectivos por embarcar ${ }^{46}$. Las 16 unidades llegaron a las costas de Liguria en agosto o septiembre de 1587. Como era habitual, se desembarcaron los soldados en Savona para evitar su concentración en Génova. Finalmente, las galeras de Nápoles completaron la misión unas semanas más tarde.

En menor medida, las galeras de los asentistas servían para transportar material militar desde Italia hacia España. Esta actividad no solía justificar la organización de una expedición, pero sí era frecuente que se aprovechase alguna travesía para cargar material procedente de Génova, Nápoles o Milán ${ }^{47}$. En 1578, los asentistas llevaron a Cartagena entre 5.500 y 7.000 picas y lanzas, casi 5.000 arcabuces, más de 3.300 frascos y frasquillos, 730 coseletes, además de una gran variedad de pertrechos navales ${ }^{48}$. Dos años más tarde, las galeras de Marcello Doria transportaron cinco cañones, piezas de artillería, y más de 12.000 balas $^{49}$. Ahora bien, el elevado peso y volumen del material de guerra no era siempre compatible con su transporte en galeras. Algunos productos, como la pólvora, eran además peligrosos ${ }^{50}$. Por eso, las galeras compartían esta tarea con naves de mayor capacidad de carga ${ }^{51}$. En 1570, las cuatro galeras de los Lomellini fueron así acompañadas por una nave ragusea para llevar a España un poco más de 1.000 arcabuces, 19 cajas de aparejos, 96 de pólvora y otras 250 de morriones ${ }^{52}$. Lo más voluminoso del cargamento iba situado en la nave.

45 En 1590, Doria confirmó este tope de 140-150 soldados por galera. Estimó que no se podía llevar a más de 4.000 soldados en 28 galeras (Gian Andrea Doria a Felipe II, AGS, EST, leg. 1422, doc. 107, 15/06/1590).

${ }^{46}$ Doria señaló en 1580 que, además de los 4.600 soldados, se habían embarcado alrededor de 1.000 mujeres y niños (Gian Andrea Doria a Felipe II, AGS, EST, leg. 1413, doc. 39, $31 / 08 / 1580)$.

47 Juan de Idiáquez a Felipe II, AGS, EST, leg. 1404, doc. 34, 07/06/1574. Pedro de Mendoza a Felipe II, AGS, EST, leg. 1413, doc. 150, 03/08/1580. Gian Andrea Doria a Felipe II, AGS, EST, leg. 1430, doc. 105, 03/07/1599. ASV, SDG, filza 6, doc. 21, 17/07/1627; doc. 40, 28/11/1631. VARGAS HIDALGO, 2002: 921, 993, 1251 y 1531-1532.

${ }^{48}$ Relación de armas, artillería y pertrechos, AGS, EST, leg. 1412, doc. 135, 09/06/1578.

49 Relación de armas y municiones, AGS, EST, leg. 1413, doc. 151, 1580.

50 Gian Andrea Doria a Felipe II, AGS, EST, leg. 1398, doc. 114, 11/10/1569.

${ }^{51}$ Por ejemplo: Póliza de carga, AGS, EST, leg. 1403, doc. 31, 16/12/1572.

52 Francisco de Ugarte a Felipe II, AGS, EST, leg. 1400, doc. 5, 24/05/1570. 


\section{Los ENVÍOS DE METALES PRECIOSOS}

El metal precioso era otro recurso de gran valor estratégico que la Monarquía necesitaba mover entre la Península Ibérica, Italia y Flandes ${ }^{53}$. La política imperial exigía que se pagaran ingentes cantidades de dinero en el continente, por lo que la Corona contrataba los servicios de agentes financieros, principalmente genoveses, para que adelantasen el dinero y lo transfiriesen a escala internacional. Para cumplir con sus asientos, las compañías bancarias acumulaban en Europa obligaciones de pago que debían extinguir exportando mercancías o plata desde Castilla, donde se les pagaba ${ }^{54}$. La salida de metales preciosos estaba prohibida durante el reinado de Carlos V, pero a partir de la década de 1550, la Monarquía empezó a conceder licencias de saca a sus banqueros $^{55}$. Era evidente que sin poder exportar plata hacia las plazas donde se endeudaban, los asentistas tendrían muchas dificultades para cubrir las crecientes necesidades crediticias de la Corona. Además, la circulación del metal precioso aumentaba su oferta en los mercados internacionales, lo que tendía a abaratar el coste del crédito donde la Monarquía precisaba dinero ${ }^{56}$. Al fin y al cabo, los Habsburgo necesitaban desplazar dinero desde las plazas donde tenían excedentes de ingresos fiscales, hacia los lugares donde estos recursos eran deficitarios ${ }^{57}$. Para solventar este problema, tenían especial interés en que el metal precioso fluyese entre los diferentes territorios del sistema imperial.

La sublevación holandesa hizo inviable enviar metal precioso por el Atlántico, al mismo tiempo que incrementó las necesidades financieras de la Corona en Flandes. La ruta mediterránea se convirtió entonces en el eje fundamental para la exportación de plata hacia Italia y el resto del continente ${ }^{58}$. En este contexto, las galeras de los asentistas genoveses fueron esenciales. A partir de 1575, la escuadra empezó a ser utilizada con regularidad para realizar transferencias masivas de dinero entre las costas españolas (principalmente desde Barcelona) y Génova. A lo largo de los años, se afianzó como la principal institución naval que los banqueros del rey utilizaban para enviar las considerables cantidades de metal que manejaban. Cada año, se organizaban uno o varios convoyes de galeras (generalmente compuestos por entre 2 a 6 unidades) que se desplazaban hacia España para cargar a varios centenares de miles de escudos. Para dar una idea del papel que la escuadra desempeñó en este ámbito, la tabla 2 señala

${ }^{53}$ Por cuestiones de extensión, este apartado presenta solo algunos aspectos de una investigación más amplia que explora la relación entre galeras, transporte de la plata y finanzas genovesas (MARÉCHAUX, 2017).

54 ÁlVAREZ NOGAL, XXIII/S1 (Madrid, 2005a): 382-384.

${ }^{55}$ CARANDE, 1990, vol. III: 370-374. RUIZ MARTÍN, 1990: 21-27 y 35-39.

56 ÁLVAREZ NOGAL, XXIII/S1 (Madrid, 2005a): 382-384.

57 ÁLVAREZ NOGAL, 2008: 191.

${ }^{58}$ BRAUDEL, 1990, vol. II: 157-163. RUIZ MARTÍN, 1999: 24. DA SILVA, 1969, vol. I: 171. 
algunas transferencias realizadas en el período 1580-1592 (con indicación de las cantidades aproximativas, que deben ser consideradas como mínimos).

TABLA 2. El transporte de plata en la escuadra de Génova (1580-1592, mínimos)

\begin{tabular}{|c|c|c|c|}
\hline Año & Travesía & Cantidad & Observaciones \\
\hline 1581 & España - Génova & 500.000 esc. & En dos travesías \\
\hline 1582 & España - Génova & s.i. & $\begin{array}{l}\text { Filippo Adorno solicitó una galera } \\
\text { de los asentistas }\end{array}$ \\
\hline 1584 & España - Génova & 4.000 .000 esc. & Dinero del rey y de banqueros \\
\hline 1585 & España - Génova & $1.500 .000 \mathrm{esc}$. & En varias travesías \\
\hline 1586 & España - Génova & 1.200 .000 esc. & $\begin{array}{c}\text { En siete galeras. Dinero del rey } \\
\text { y de banqueros }\end{array}$ \\
\hline 1587 & España - Génova & 900.000 esc. & \\
\hline 1588 & España - Génova & 2.800 .000 esc. & En varias travesías \\
\hline 1589 & España - Génova & 700.000 esc. & \\
\hline 1590 & España - Génova & 1.000 .000 esc. & En nueve galeras \\
\hline 1592 & España-Génova & 2.400 .000 esc. & En cuatro galeras \\
\hline
\end{tabular}

Fuentes: PALLAVICINO, 1975: 50, 70, 107 y 123. BRAUDEL, 1990, vol. II: 167-169. RUIZ MARTÍN, 1990: 38. RUIZ MARTÍN, 1999: 28-29. VARGAS HIDALGO, 2002: 1128-1131, 1151-1157 y 1180-1184. Benedetto y Bernardino Bonvisi a Simón Ruiz, ASR, caja 70, doc. 56, 06/04/1581. Francesco Lamberti a Simón Ruiz, ASR, caja 112, doc. 136, 08/06/1586. Gian Andrea Doria a Felipe II, AGS, EST, leg. 1420, doc. 145, 25/03/1588. Alessandro, Nicolò y Ottaviano Diodati a Simón Ruiz, ASR, caja 143, doc. 276, 22/12/1590. Filippo Cattaneo y Ambrogio Gentile a Simón Ruiz, ASR, caja 156, doc. 175, 19/05/1592. Paolo Salvago a Felipe II, AGS, EST, leg. 1424, doc. 191, 04/05/1592.

El uso de las galeras genovesas para el transporte de metal precioso era el resultado de acuerdos contractuales entre la Corona y sus banqueros. A raíz de los cambios surgidos con la revuelta holandesa, los negociantes genoveses hicieron el cálculo siguiente: para transportar cantidades tan elevadas de plata hasta Génova, y hacerlo de forma económica y segura ¿no existía alguna forma de utilizar las galeras que ellos mismos, los genoveses, ponían al servicio del rey? En estas circunstancias, empezaron a negociar la cesión de las galeras en los asientos de dinero de mayor importe, algo que consiguieron plenamente con el Medio General de $1577^{59}$. A partir de entonces, lo habitual era

${ }^{59}$ CARLOS MORALES, 2016, vol. II: 66-67. 
que cada año, la Monarquía y los banqueros incluyesen en los contratos más importantes una cláusula que garantizaba el uso de las galeras para las transferencias de dinero a través del Mediterráneo. La Corona se comprometía concretamente a: 1) ceder un número determinado de galeras genovesas, una o varias veces al año, para el transporte de la plata; 2) concederlas en las fechas que los principales asentistas eligiesen; 3) no exigir ningún derecho de flete sobre la plata exportada ${ }^{60}$.

Estas cláusulas reflejan el poder de negociación de los genoveses, a la vez que muestran cómo la Corona estaba dispuesta a movilizar galeras de su flota para que el metal precioso cruzase el Mediterráneo en las mejores condiciones posibles. De la seguridad y del buen desarrollo de las transferencias dependían los mercados de crédito en Italia y la financiación de los ejércitos del Rey, especialmente en Flandes. Al ser buques de guerra costeados por la Monarquía, las galeras de los asentistas presentaban ventajas considerables en términos de protección y de costes. Permitían transportar y proteger mercancías de elevado valor en un contexto de alta inseguridad marítima, sin tener que pagar por ello un precio alto ${ }^{61}$. Entre las décadas de 1570 y 1640, el servicio prestado por estas galeras fue, en el ámbito del transporte de la plata, de muy alta calidad. A pesar de la inseguridad que predominaba en el Mediterráneo, garantizaron niveles de protección muy elevados. La Corona, los altos mandos navales genoveses y los banqueros supieron además coordinarse de tal forma que se disponía de las galeras cuando más se necesitaban. Por último, el transporte de la plata por parte de los asentistas de galeras genoveses, que tenían mucha conexión con el mundo de las finanzas, generaba confianza en los mercados crediticios italianos.

Mediante la intermediación de los banqueros genoveses de Madrid, que eran los grandes protagonistas de la ruta de la plata, la logística del transporte involucraba a diferentes tipos de agentes que participaban en el proceso desde la captación del metal precioso en la Península Ibérica, hasta su llegada a los palacios de la oligarquía genovesa. La transferencia de dinero a través del Mediterráneo implicaba coordinar la actividad de múltiples individuos, manejar información compleja, y gestionar recursos a escala internacional ${ }^{62}$. Los merchant bankers de Madrid debían contratar a los comisarios y arrieros que llevaban el dinero a los puertos de embarque, tratar con la Corona para solicitar las galeras, mantener correspondientes en los puertos de embarque para obtener información y gestionar la plata, negociar, algunas veces, con los capitanes de galeras, y evidentemente, coordinarse con sus colaboradores de Génova

\footnotetext{
${ }^{60}$ AGS, CCG, leg. 87, 89, 91, 96, 100, 102, 107, 111-112, 116-119, 124 y 130 (1575-1636).

${ }^{61}$ Como es bien sabido, las galeras eran un barco excelente para transportar bienes de alto valor (LANE, 1965: 5).

62 ÁlVAREZ NOGAL, LO BASSO y MARSILIO, 124/1 (Bolonia, 2007): 97-110.
} 
(por ejemplo, para adquirir las pólizas de seguro). En todo este proceso, los negociantes colaboraban al mismo tiempo que competían entre sí para enviar la plata a bordo de las galeras. Por su lado, los Doria, los asentistas de galeras y los capitanes debían preparar cuidadosamente las embarcaciones, organizarse de tal modo que se respetasen los tiempos requeridos por los banqueros y, sobre todo, garantizar la seguridad del convoy durante la travesía. Los días efectivos de navegación eran breves (en principio, alrededor de unos 4-6 días), pero debido a la necesidad de limitar los riesgos (causados por el mal tiempo o las amenazas de captura), los tiempos de espera eran largos y las operaciones solían durar varias semanas. Una vez el metal precioso llegaba a Génova, se entregaban las cajas a los socios y acreedores y a través de ellos, se redistribuía el dinero hacia una multitud de agentes y plazas de Europa.

\section{LA CIRCULACIÓN DE LAS ÉLITES IMPERIALES}

Estudios recientes han puesto de manifiesto la existencia de unas élites imperiales cuyos enlaces familiares, actividades políticas y prácticas culturales superaban y atravesaban las fronteras de los múltiples territorios controlados por la Corona. Estas «redes del imperio», que complementaban las relaciones verticales de poder para dotar a la Monarquía de una mayor cohesión sociopolítica, se sustentaban en la movilidad geográfica de sus miembros. El poder imperial promovió la circulación de estas familias mediante una ambiciosa política de cargos y mercedes ${ }^{63}$. Menos conocido es que los Habsburgo pusieron también interés en dedicar una parte relevante de sus recursos navales al transporte de dichas élites. Con la cesión de las galeras para este fin, la Corona ponía buques de guerra a disposición de sus miembros de gobierno, quienes podían de este modo viajar con total seguridad ${ }^{64}$. Las galeras eran también un medio de transporte de alto valor honorífico. Realizar la travesía en estas embarcaciones del rey era un elemento de distinción social, porque hacía visible la pertenencia a las altas esferas de poder imperial. Los altos mandos de la escuadra como los Doria aprovechaban estas travesías para cultivar su capital social y político tratando con las élites del imperio $^{65}$. Otras escuadras participaron de este esfuerzo de articulación territorial a través del transporte de las élites, pero la de los genoveses fue la más utilizada. La ruta mediterránea que conectaba los territorios hispánicos pasaba por Génova, lo que incitaba a recurrir a ella. Con el paso de los años, los Doria adquirieron además experiencia en estos servicios.

\footnotetext{
${ }^{63}$ YUN CASALILLA, 2009.

${ }^{64}$ LOMAS CORTÉS, 2011: 198.

${ }^{65}$ LOMAS CORTÉS, 2012.
} 
Ya en 1529, Carlos V había sido llevado de Barcelona a Génova por las galeras de Andrea Doria, las mismas que le trajeron de vuelta cuatro años más tarde. El emperador repitió travesías a bordo de estas unidades en los años $1535-1536,1538,1541$ y 1543. A su vez, su heredero las solicitó para alcanzar Génova en 1548, y volvió del mismo modo después de su viaje por los Países Bajos y Alemania $^{66}$. Las galeras de los asentistas genoveses transportaron también en varias ocasiones a miembros del entorno real. Por ejemplo, en 1548, embarcó en ellas el futuro emperador Maximiliano; en 1581, la emperatriz María de Austria; cuatro años después lo hicieron Carlos Manuel de Saboya y la infanta Catalina de Austria, hija del rey Felipe II; por último, en 1599, la reina Margarita y el archiduque Alberto ${ }^{67}$.

De forma más ordinaria, las galeras eran empleadas para transportar a los ministros de la Corona destinados a ejercer algún cargo político fuera de la Península Ibérica. El gobernador de Milán y los virreyes de Nápoles, Cerdeña y Sicilia, así como los embajadores españoles en Italia, solían pedir que la Corona pusiese galeras a su disposición. Los miembros de la gran nobleza imperial, élites eclesiásticas incluidas, podían también solicitarlo. Al fin y al cabo, era importante contentar a aquellas personalidades que trabajarían por la Monarquía o, al menos, tratarían con ella. Sin que fueran organizadas expediciones específicas para ellos, la Corona accedía también a que élites de todo tipo (oficiales, mercaderes, eclesiásticos, militares...) aprovechasen las continuas travesías de las galeras para embarcar en ellas, y cruzar así el Mediterráneo ${ }^{68}$. Los propios genoveses no desperdiciaban estas oportunidades, estando siempre pendientes del próximo «pasaje de galeras» ${ }^{69}$. De esta manera, las galeras solían llevar a muchos pasajeros cada vez que salían en el $\operatorname{mar}^{70}$. Al fin y al cabo, su función como puente entre las penínsulas italiana y española reforzaba la posición de Génova como puerta de entrada y salida hacia España.

Para dar una idea del movimiento de las galeras, se puede tomar el ejemplo de las travesías que, con este fin, las unidades de Carlo Doria realizaron durante los períodos de invierno comprendidos entre 1600 y 1622. La tabla 3 ilustra cómo la escuadra servía para garantizar una circulación continua de las élites.

\footnotetext{
${ }^{66}$ FERNÁNDEZ DURO, 1893. PACINI, 1999.

${ }^{67}$ FERNÁNDEZ DURO, 1893. LOMAS CORTÉS, 2012.

${ }^{68}$ Numerosas referencias en VARGAS HIDALGO, 2002. AGS, EST, serie Génova. ASCG, MBS, ms. 109 D4.

${ }^{69}$ Cartas a Nicolò Di Negro, ADM, n. $.^{\circ} 183,23 / 01 / 1606$ y 21/02/1606. Para ir a España, Ottavio Centurione se embarcó en dos galeras de la escuadra que debían servir, a la vuelta, para llevar al Marqués Ambrogio Spinola.

${ }^{70}$ Gian Andrea Doria a Felipe II, AGS, EST, leg. 1422, doc. 107, 15/06/1590.
} 
TABLA 3. El transporte de élites en las galeras de Carlo Doria (1600-1622, inviernos)

\begin{tabular}{|c|c|c|c|c|}
\hline Período & Individuo & Procedencia & Destino & Cargo \\
\hline $1600-1601$ & $\begin{array}{l}\text { Condestable } \\
\text { de Castilla }\end{array}$ & Liguria & España & $\begin{array}{l}\text { Gobernador } \\
\text { en Milán }\end{array}$ \\
\hline 1603-1604 & Duque de Sessa & Civitavecchia & España & Embajador en Roma \\
\hline $1605-1606$ & Giannettino Doria & & Civitavecchia & Cardenal \\
\hline $1607-1608$ & $\begin{array}{c}\text { Giovanni Garzia } \\
\text { Mellini }\end{array}$ & España & Civitavecchia & Cardenal / nuncio \\
\hline $1610-1611$ & $\begin{array}{l}\text { Condestable de } \\
\text { Castilla }\end{array}$ & Liguria & España & $\begin{array}{l}\text { Gobernador } \\
\text { en Milán }\end{array}$ \\
\hline $1612-1613$ & Gaspar de Borja & & Civitavecchia & Cardenal \\
\hline $1613-1614$ & Pedro de Leiva & Génova & Nápoles & $\begin{array}{c}\text { Capitán General de } \\
\text { la escuadra de Sicilia }\end{array}$ \\
\hline $1615-1616$ & $\begin{array}{l}\text { Marqués de la } \\
\text { Hinojosa }\end{array}$ & Liguria & España & $\begin{array}{l}\text { Gobernador } \\
\text { de Milán }\end{array}$ \\
\hline $1617-1618$ & Carlos de Borja & Cerdeña & & Virrey de Cerdeña \\
\hline $1618-1619$ & Marqués de Este & & Ambucar & \\
\hline $1619-1620$ & $\begin{array}{c}\text { Duque de } \\
\text { Alburquerque }\end{array}$ & Mesina & Civitavecchia & $\begin{array}{l}\text { Embajador } \\
\text { en Roma }\end{array}$ \\
\hline $1620-1621$ & Antonio Zapata & Marsella & Civitavecchia & Virrey de Nápoles \\
\hline $1620-1621$ & $\begin{array}{l}\text { Princesa de } \\
\text { Módena }\end{array}$ & España & & Princesa \\
\hline $1621-1622$ & $\begin{array}{l}\text { Conde de } \\
\text { Monterrey }\end{array}$ & Génova & Civitavecchia & \\
\hline
\end{tabular}

Fuente: AGS, GAL, leg. $31^{71}$.

Este tipo de expediciones tenía también sus exigencias. Transportar élites de gobierno requería preparar los barcos, garantizar la seguridad del convoy, gestionar los tiempos, lidiar con los aristócratas que viajaban, seleccionar los acompañantes invitados a bordo, e incluso, convertir las galeras en un espacio de representación del poder conforme con el estatus de los viajeros ${ }^{72}$. El traslado de la emperatriz María de Austria el año de 1581 permite arrojar luz sobre

\footnotetext{
${ }^{71}$ Esta reconstrucción se ha realizado utilizando los certificados de invernada (período comprendido entre el 15 de octubre y el 15 de marzo).

${ }^{72}$ Un buen ejemplo en LOMAS CORTÉS, 2012.
} 
algunos de estos aspectos ${ }^{73}$. En su primera carta a Gian Andrea Doria sobre el asunto, en mayo de 1581, Felipe II subrayó la importancia de una misión que involucraba a su propia hermana, y advirtió al genovés de que debía preparar todo de manera que la emperatriz «no tenga porque detenerse una hora (sic) $\rangle^{74}$. En realidad, planificar los tiempos de estas travesías era una tarea ardua, ya que la fecha de llegada de los viajeros solía resultar muy incierta ${ }^{75}$. En este caso, María de Austria estaba todavía en Praga, y nadie sabía cuándo llegaría a Génova. A pesar de ello, Doria empezó con los preparativos, organizó la reunión de las galeras y aparejó su «Capitana grande» para que el viaje resultase del gusto de la pasajera. En este tipo de expediciones, hacía falta adquirir toda una serie de alimentos, bienes y ornamentos varios para que la galera se convirtiese en un espacio de celebración ${ }^{76}$.

Mientras tanto, Felipe II comunicó su preocupación por los problemas de seguridad derivados de las actividades del capitán general de la flota otomana, Uluç Alí. Algunos avisos señalaban que el Kapudan Paşa podría entrar en el Mediterráneo Occidental con más de 60 galeras a lo largo de los siguientes meses, lo que suponía una amenaza para la protección de las costas españolas, y para la seguridad de la propia emperatriz $z^{77}$. Se ordenó que unas veinte galeras de la escuadra de Nápoles se juntasen con la de Génova, y que se embarcasen dos compañías de infantería. Debido a las asimetrías de información a las cuales estaba sujeto desde Lisboa, Felipe II delegó en Doria la responsabilidad de adaptar la misión en función de los movimientos de Uluç Alí. En realidad, no se trataba de ningún favor: el rey ordenaba a Doria que acudiese, en caso de peligro, a defender las costas españolas, a la vez que le prohibía que su hermana esperase en Génova.

En julio se informó de que la emperatriz llevaría 200 caballos y muchos objetos personales, lo que obligó a fletar cinco naves comerciales. Sobre todo, la acompañaba un séquito de más de 600 personas que haría falta embarcar y gestionar. Los preparativos (barcos, dinero, infantería...) se estaban ultimando, cuando en septiembre, Felipe II pidió a Doria que enviara urgentemente las galeras hacia España, donde se temía una expedición de Uluç Alí. El genovés decidió no cumplir esta orden. Argumentó que las noticias más recientes sobre

${ }^{73}$ Para lo que sigue, véase Correspondencia entre Felipe II, Gian Andrea Doria y Pedro de Mendoza, AGS, EST, leg. 1414-1415. VARGAS HIDALGO, 2002: 1070-1095. Para el viaje de María en su conjunto, véase SCHODER, 1999.

${ }^{74}$ Felipe II a Gian Andrea Doria, AGS, EST, leg. 1415, doc. 130, 14/05/1581.

75 Doria tendría el mismo problema para el viaje de la reina Margarita en 1599 (LOMAS CORTÉS, 2012: 198-201).

${ }^{76}$ Un ejemplo de gastos de este tipo en AGS, GAL, leg. 205 (viaje de los Príncipes de Saboya).

77 Sobre el temor hacia los movimientos de Uluç Alí en 1581, véase SOLA CASTAÑO, 2010: 327-342. 
Uchali lo situaban de vuelta hacia Levante, y que María de Austria estaba a punto de llegar. Para cumplir con los objetivos marcados, Doria dividió el convoy en dos tiempos. Envió primero a la escuadra de Nápoles con una parte de la infantería, mientras él se quedó esperando a la emperatriz. Esta decisión fue tomada sin contar con la opinión de María, que mostró su descontento porque no todas las galeras la habían esperado. El genovés tuvo que rectificar y ordenó a la escuadra de Nápoles que parase hasta la llegada del resto del convoy.

La hermana del rey llegó finalmente a Génova el 15 de octubre de 1581, aunque el mal tiempo la obligó a esperar tres semanas antes de salir. Doria había advertido siempre sobre la necesidad de realizar el viaje antes del invierno, pero su consejo no había surtido efecto. Junto con el embajador español Pedro de Mendoza, procuraron atender a la emperatriz, al mismo tiempo que realizaron gestiones para contener el amotinamiento de la infantería. Mientras tanto las galeras estuvieron muy expuestas a los peligros de la mar, ya que, debido a la presencia de los soldados, la República de Génova no había permitido que la escuadra entrase en su dársena. Después de meses de preparación, la emperatriz embarcó finalmente el 5 de noviembre. Las galeras de Génova y de Nápoles navegaron hasta que el mal tiempo obligó a hacer una escala forzada en Marsella. La parada no fue del gusto de María de Austria, que quiso proseguir su viaje por caminos de tierra a pesar de los riesgos que eso suponía. Debido a las precarias condiciones de navegación (tiempo, espacio reducido, mareos...), los pasajes en galeras resultaban a menudo duros para los viajeros, especialmente en invierno. Convencida por su entorno de la imposibilidad de la opción planteada, la emperatriz accedió finalmente a volver a las galeras de los asentistas, y llegó a Colliure a principios de diciembre del año de 1581. Por los largos tiempos de preparación, los riesgos derivados de la inseguridad, la difícil coordinación y los problemas de disciplina, esta travesía ilustra a la vez las dificultades y los esfuerzos logísticos requeridos por misiones de este tipo y recuerda a la efectuada por la reina Margarita en 1598-1599, tal y como ha sido estudiada recientemente ${ }^{78}$.

\section{LA TRANSMISIÓN DE LA INFORMACIÓN}

Es bien sabido que la dispersión de los territorios hispánicos dificultaba la transmisión de la información entre los órganos de poder del imperio, y que este «factor distancia» afectaba al proceso de toma de decisiones a escala glo$\mathrm{bal}^{79}$. En el día a día de la práctica de gobierno, la dependencia hacia los

\footnotetext{
${ }^{78}$ LOMAS CORTÉS, 2012.

79 BRAUDEL, 1990, vol. II: 9-56. PARKER, 1998: 103-144. GAUDIN, 2013. GAUDIN, CASTILLO GÓMEZ, GÓMEZ GÓMEZ y STUMPF, 2017.
}

Hispania, 2020, vol. LXXX, n. ${ }^{\circ}$ 264, enero-abril, págs. 47-77, ISSN: 0018-2141, e-ISSN: 1988-8368 
servicios postales era tal que la cuestión de la llegada de un correo era a menudo la primera preocupación de los ministros. "La monarquia de $\mathrm{Su}$ Majestad [es] tan dilatada y dividida [que] depende mucha parte de su govierno de la puntualidad de los correos (sic)», declaró el embajador español en Génova en $1633^{80}$. No le faltaba razón al enviado diplomático que, de todos modos, no dejaba de recordar un axioma político conocido de todos. Es fácil entender que la articulación de un imperio global como el hispánico pasaba por contar con un buen sistema de comunicaciones.

En lo que concierne a Italia y al mundo mediterráneo, la Corona desarrolló a lo largo del siglo XVI un ambicioso sistema postal cuyo eje principal seguía las costas desde Barcelona hasta Nápoles. Más adelante, también se utilizó el camino que conectaba Madrid a Génova pasando por Burgos, Irún y Lyon ${ }^{81}$. Estas rutas terrestres eran las más utilizadas ya que garantizaban menores intervalos en los tiempos de transporte. Pese a ello, la ruta mediterránea nunca dejó de ser importante. Para la Corona, era de fundamental importancia disponer de una vía marítima que conectase directamente la Península Ibérica con la italiana. A partir de la escala genovesa, principal nudo informativo del imperio en Italia, los correos podían tomar rumbo tanto hacia el resto de Italia (Milán, Roma, Nápoles...) como hacia el norte de Europa (Alemania y los Países Bajos).

En estas circunstancias, las galeras genovesas jugaron un papel relevante. Para enviar algún correo urgente, siempre cabía la posibilidad de despachar una galera. Desde Augsburgo, en 1548, Carlos V solicitó los servicios de Andrea Doria para que trasmitiese un importante correo a su hijo y heredero, Felipe. El capitán general recibió la orden de enviar una galera a Barcelona con este único propósito ${ }^{82}$. En 1575, Gian Andrea Doria ordenó a Geronimo Malagamba, capitán de la galera de Bendinelli Sauli, que se desplazase hasta Barcelona para despachar una carta destinada a la Corte. Allí, el oficial debía esperar la respuesta antes de volver con la misma a Génova ${ }^{83}$. Esta práctica se repitió en otras ocasiones, como en 1631, cuando una galera de Doria «espressamente ispedita [...] in gran diligenza» fue enviada a Barcelona para despachar un correo procedente de Alemania. Unas semanas después, las galeras realizaron otra ida y vuelta con el mismo propósito ${ }^{84}$.

A los envíos urgentes realizados en circunstancias especiales, se añadía un uso más común de las galeras. La práctica habitual consistía en aprovechar sus

\footnotetext{
${ }^{80}$ Francisco de Melo a Pedro de Arce, AGS, EST, leg. 3591, doc. 71, 25/06/1633.

${ }^{81}$ CODOGNO, 1623: 433. MONTAÑEZ MATILLA, 1953.

${ }^{82}$ Andrea Doria al Príncipe Felipe, AGS, EST, leg. 1380, doc. 130, 04/05/1548. La galera se enfrentó a vientos en contra a su llegada a Cataluña, y tardó finalmente más de lo previsto.

${ }^{83}$ Gian Andrea Doria a Felipe II, AGS, EST, leg. 1407, doc. 187, 31/07/1575. Instrucción al capitán Geronimo Malagamba, AGS, EST, leg. 1407, doc. 188, 31/07/1575.

${ }^{84}$ ASV, SDG, filza 6 bis, doc. 9, 06/04/1631; doc. 29, 02/10/1631; doc. 30, 05/10/1631. Consulta del Consejo de Estado, AGS, EST, leg. 3590, doc. 81, 09/10/1631.
} 
continuos viajes para transportar correos a bordo. Este modus operandi no suponía ningún coste adicional para la Corona, ni perjudicaba a misiones asignadas a la escuadra. Carecía de la regularidad de los correos ordinarios, pero las idas y vueltas de las galeras eran frecuentes, y en este sentido, cualquier travesía ofrecía una buena oportunidad. Al ser informado de la próxima salida de las galeras, el rey, pero también cualquier ministro, mercader, capitán o embajador, aprovechaba la ocasión ${ }^{85}$. Así, se cargaban las galeras con muchos correos. Por ejemplo, en 1629, llegaron en una galera de Carlo Doria 22 mazos de cartas del rey dirigidos a Sicilia, Nápoles, Roma, Milán y Flandes, además de la correspondencia de otros ministros y agentes privados ${ }^{86}$.

De esta forma, las galeras servían como medio complementario. Confiar solo en la vía marítima era algo arriesgado, pero utilizarla de forma adicional a la vía terrestre tenía interesantes ventajas. Desde Madrid, Flandes, o Roma, se solían enviar varias copias que, una vez llegadas a Génova o Barcelona, tomaban su respectivo camino. Una parte de los correos pasaba por el camino de tierra, mientras que la otra seguía la ruta marítima ${ }^{87}$. La formación de los asentistas era la que realizaba el trayecto Barcelona-Génova con mayor frecuencia, por lo que su papel en este ámbito era mayor que el de otras escuadras. Ahora bien, su función era todo, menos exclusiva. Era también muy habitual utilizar pequeñas embarcaciones (como tartanas o fustas) para enviar correos a través del Mediterráneo ${ }^{88}$. Los mensajeros elegían el tipo de barcos en función de su disponibilidad en el momento ${ }^{89}$. En definitiva, las galeras genovesas nunca tuvieron el monopolio sobre dichas actividades, si bien es cierto que, por otro lado, iban cargadas de cartas cada vez que realizaban una travesía.

Las galeras tenían un papel más activo cuando el aumento de las tensiones geopolíticas amenazaba la comunicación por los caminos terrestres. Particularmente sensible era el tramo que unía los Pirineos y los Alpes mediante Francia, Saluzzo y Saboya. Durante la primera guerra de Monferrato (1613-1617), se cerraron los caminos que conectaban Liguria con el sur de Francia. Además, las fuerzas navales saboyanas procuraban capturar las embarcaciones que llevaban correos por vía marítima. La Corona replicó utilizando las galeras

${ }^{85}$ Andrea Doria a Juan de Austria, AGS, EST, leg. 1387, doc. 44-45, 18/06/1558. Pedro de Mendoza a Felipe II, AGS, EST, leg. 1417, doc. 32, 06/05/1583; Pedro de Mendoza a Felipe II, AGS, EST, leg. 1426, doc. 13, 04/02/1594. ASV, SDG, filza 6 bis, doc. 178, 24/06/1633; doc. 226, 03/01/1634. VARGAS HIDALGO, 2002: 1210, 1290, 1331, 1354 y 1388.

${ }^{86}$ ASV, SDG, filza 6, doc. 186, 18/10/1629.

${ }^{87}$ PARKER, 1998: 105. Minuta de despacho a Juan de Idiáquez, AGS, EST, leg. 1405, doc. 53, 31/08/1575.

${ }_{88}$ Andrea Doria a Juana de Austria, AGS, EST, leg. 1384, doc. 245-246, 05/04/1555. CODOGNO, 1616: 92-93. ASV, SDG, filza 6 bis, doc. 5, 23/03/1631.

89 En su manual, Codogno explicó que convenía utilizar una tartana «quando no vi sia passaggio di galere» (CODOGNO, 1616: 92).

Hispania, 2020, vol. LXXX, n. ${ }^{\circ}$ 264, enero-abril, págs. 47-77, ISSN: 0018-2141, e-ISSN: 1988-8368 
genovesas para llevar las cartas y proteger las embarcaciones menores que se dedicaban a esta tarea. Entre 1615 y 1618, entre tres y cinco galeras operaron entre Mónaco y Génova, «haziendo escolta a los correos que yvan y venian de España (sic) $\rangle^{90}$. Con el conflicto entre Saboya y Génova (1625) y la segunda guerra del Monferrato (1627-1631), los caminos postales de Saboya y Francia quedaron también impracticables ${ }^{91}$. Ocurrió lo mismo a partir de 1635 , aunque en época de guerra directa con Francia, se consideró poco oportuno que la escuadra de Génova se dedicase a escoltar correos. Los ministros españoles prefirieron contratar tartanas que debían asegurar una conexión postal bimensual entre Génova y Barcelona ${ }^{92}$. Aun así, no se renunció al servicio de las galeras. En 1635, los expertos solicitados por el Consejo de Estado lo notificaron: «Adviertese, que haviendo galeras, no se dexen de embarcar los correos en ellas, pues es con mayor seguridad, y presteza (sic) $\Downarrow^{93}$. Además, el sistema de tartanas no funcionó bien debido a la falta de fondos ${ }^{94}$. En este contexto, las galeras resultaban útiles para transportar los correos ${ }^{95}$.

La circulación de la información económica era también esencial para la articulación imperial. La Corona sabía cuánto dependían los servicios de sus banqueros de los correos, y particularmente, de los que se intercambiaban entre Madrid, Génova, y las ferias de cambio italianas ${ }^{96}$. Por eso, les permitía utilizar sus servicios postales y se coordinaba con ellos ${ }^{97}$. Como en el ámbito de la correspondencia política, las galeras de los asentistas jugaban un papel complementario a las rutas terrestres. En las décadas de 1580-1590, los correspondientes de los Ruiz en Génova utilizaron a menudo este medio para enviar sus correos. Cuando las galeras salían con destino a España, los Balbi, Cattaneo o Bonvisi lo aprovechaban. Era también frecuente que enviasen una copia por vía terrestre, y otra por vía marítima ${ }^{98}$. En algunas ocasiones, se entregaba incluso el correo a algún compatriota. Así, en 1609, Gio. Francesco

90 AGS, GAL, leg. 29, doc. 9, 22/03/1618.

91 ASV, SDG, filza 6 bis, doc. 116, 14/11/1632.

${ }_{92}$ Accordatio tartana, ASG, NA, filza 7146, 07/04/1635. Consulta del Consejo de Estado, AGS, EST, leg. 3592, doc. 93, 31/08/1635.

${ }_{93}$ Parecer de ministros, AGS, EST, leg. 3592, doc. 94, 1635.

${ }_{94}$ Consultas del Consejo de Estado, AGS, EST, leg. 3594, doc. 16, 17/09/1637; doc. 35, 20/10/1637.

95 ASV, SDG, filza 6 ter, doc. 82, 01/09/1635; doc. 99, 05/11/1635.

96 Sobre la cuestión, véase ÁLVAREZ NOGAL, LO BASSO y MARSILIO, 124/1 (Bolonia, 2007): 97-110.

${ }_{97}$ Billete de Pedro Arce, AGS, EST, leg. 3590, doc. 159, 20/12/1632. Mientras el gobierno central estaba a punto de enviar cartas a Génova, esta nota interna indicó que los despachos de los hombres de negocios no estaban todavía listos, y que «si partiese el correo sin ellos, seria gran falta».

98 Filippo y Giacomo Cattaneo a Simón Ruiz, ASR, caja 143, doc. 240 y 260, 21/02/1590 y 28/09/1590. 
Pallavicini confió sus cartas a Domingo de Alcivar y Adamo Centurione, quiénes estaban a punto de embarcarse en las galeras de Carlo Doria y de Vincenzo Centurione ${ }^{99}$. Cuando llegaban a Génova o Barcelona, las galeras llevaban decenas de cartas de los negociantes ${ }^{100}$. El uso de las galeras para la información comercial era también relevante en tiempo de guerra. La correspondencia de los Pallavicini en la década de 1630 lo atestigua ${ }^{101}$. Por último, las galeras podían ser utilizadas para transportar las letras de cambio y los spacci di fiera antes y después de las ferias de Piacenza ${ }^{102}$.

\section{Conclusión}

La escuadra de los particulares genoveses es un buen ejemplo de institución transnacional utilizada por la Monarquía Hispánica para fomentar la articulación de su imperio. Con datos de archivo, este artículo ha mostrado cómo, entre la segunda mitad del siglo XVI y la primera mitad del XVII, la formación hispano-genovesa fue crucial para el transporte de dinero, soldados, armas, élites de gobierno e información entre las costas españolas e italianas. La Corona tenía necesidad de contar con estos recursos en diferentes centros del conglomerado imperial, pero al ser su distribución desigual y no proporcional con la demanda, hacía falta moverlos desde las plazas donde había abundancia, hacia donde había escasez. Dicho de otro modo, las galeras se dedicaban a mover continuamente bienes y personas cuya circulación era necesaria para la administración de un imperio de naturaleza policéntrica. Al fin y al cabo, de su actividad dependía la conexión (política, financiera, y militar) entre España, Italia y Flandes, y concretamente, entre ciudades como Génova, Barcelona, Cartagena, Madrid, Nápoles, Milán y Amberes. No en vano, patricios locales, mercaderes, cónsules y embajadores daban repetidamente cuenta en sus diarios y cartas de los movimientos de unas galeras cuya llegada a puerto solía ser noticia debido al carácter estratégico de lo que traían y de lo que llevaban.

En la época moderna, la razón de ser de las flotas navales radicaba en el control de determinadas líneas marítimas de comunicación ${ }^{103}$. Desde este punto de vista, es indudable que la escuadra hispano-genovesa fue clave para que la Corona ejerciese el dominio sobre una ruta que constituía una de las principales

99 Gio. Luca Pallavicini a Gio. Francesco Pallavicini, ADGG, PAL RP, n. ${ }^{\circ}$ 208, 28/08/1609.

100 Por ejemplo, ASV, SDG, filza 6 bis, doc. 226, 03/01/1634.

101 Paolo Gerolamo Pallavicini a Gio. Luca Pallavicini, ADGG, PAL RP, n. ${ }^{\circ}$ 304, 03/07/1634. Paolo Gerolamo Pallavicini a Pelegro Berardo, ADGG, PAL RP, n. ${ }^{\circ}$ 304, 30/04/1635. Carlo Strata a Paolo Gerolamo Pallavicini, ADGG, PAL RP, n. ${ }^{\circ} 221,17 / 01 / 1636$.

102 Cartas de Gio. Luca Pallavicini a Gio. Francesco Pallavicini, n.o 210, 28/07/1611; n. ${ }^{\circ} 213,17 / 04 / 1613$. MARSILIO, 2008: 37.

${ }^{103}$ GLETE, 2000: 1.

Hispania, 2020, vol. LXXX, n. ${ }^{\circ}$ 264, enero-abril, págs. 47-77, ISSN: 0018-2141, e-ISSN: 1988-8368

https://doi.org/10.3989/hispania.2020.002 
arterias del imperio. Sin considerar dicha labor, sería imposible entender cómo los Habsburgo pudieron integrar sus dominios españoles e italianos dentro del sistema imperial, o cómo fueron capaces de desplazar y financiar sus ejércitos europeos durante la guerra de los Ochenta Años. Mediante el uso de sus barcos de guerra para transportar recursos estratégicos, la Corona pretendía maximizar la seguridad de estas transferencias y minimizar sus costes de transporte. En otros términos, conseguir economías de escala. Esta ambición era, también, un reto. Implicaba compatibilizar actividades militares y logísticas y enlazar continuamente misiones de diferentes tipos, algo que no se cumplía siempre de la mejor forma. Aparejar galeras era un proceso muy lento, las unidades no estaban siempre disponibles, la coordinación planteaba problemas y los riesgos del mar, difíciles de prever, complicaban aún más las cosas. Sin embargo, los resultados de esta investigación, acordes con otro caso de estudio ${ }^{104}$, muestran que la escuadra realizó una labor considerable al respecto y fue capaz de integrar estas diferentes actividades. En este sentido, este trabajo proporciona un argumento más a favor de la utilidad estratégica de las galeras incluso después de la década de $1570^{105}$. Su función iba más allá de la guerra en el mar e, incluso, del mundo mediterráneo, ya que una parte relevante de los recursos transportados provenían del norte de Europa o estaban destinados a él.

Aunque era la que más contribuía a conectar diferentes territorios de la Corona en el Mediterráneo, la escuadra genovesa no era la única en hacerlo, $\mathrm{y}$, de hecho, su actividad se hacía a menudo en colaboración, o de forma complementaria, a la de otros medios de transporte. Desde este punto de vista, resulta muy interesante observar cómo otras escuadras de galeras cumplían con funciones muy similares. El análisis del papel jugado por la de España para aprovisionar el doble presidio de Orán-Mazalquivir corrobora la existencia de unas prácticas logísticas consolidadas y repetidas que, aunque a diferentes escalas, servían para conectar las tierras imperiales por mar mediante el transporte del mismo tipo de recursos (dinero, trigo, soldados, armas...). Esta actividad suponía también hacer frente a unos obstáculos marítimos y organizativos muy parecidos $^{106}$. Sin lugar a duda, estas escuadras eran piezas dentro de un dispositivo mucho más amplio que se extendía a escala mundial. En el futuro, sería de interés profundizar sobre este problema desde una perspectiva comparada y global.

Para contribuir al reto que suponía gobernar un imperio global, la Monarquía confió mucho en una escuadra cuyos gestores eran tal vez más expertos en la movilización de recursos a escala internacional que en el ejercicio de la guerra. Esta investigación corrobora los estudios que, a lo largo de los últimos

\footnotetext{
104 LOMAS CORTÉS, 2011: 204.

105 Sobre este último aspecto, véase LO BASSO, 2003: 11-12.

106 LOMAS CORTÉS, 2011.
} 
años, han enfatizado cuánto la consolidación del poder imperial, durante la primera globalización hispánica, se debió en gran medida a su colaboración con una plétora de agentes, redes e instituciones transnacionales que participaron directamente del Global Empire Building ${ }^{107}$. En este sentido, la naturaleza de la escuadra de los asentistas - basada en la contratación de armadores procedentes de otro territorio- es elocuente. El análisis concreto de sus operaciones revela una imagen aún más llamativa. Se ha visto cómo implicaban una multitud de agentes (gobernantes, altos mandos navales, asentistas, capitanes de galeras, comisarios, embajadores, banqueros, correspondientes mercantiles, mensajeros, soldados...) que colaboraban entre sí, ponían sus redes al servicio de la Monarquía, y, al fin y al cabo, participaban de una forma u otra en la articulación naval de un imperio policéntrico.

\section{Biblogr AFÍA}

Álvarez Nogal, Carlos, «El transporte de moneda en la España del siglo XVII: mecanismos y costes», Revista de Historia Económica, XXIII/S1 (Madrid, 2005a): 379-408.

Álvarez Nogal, Carlos, «Las compañías bancarias genovesas en Madrid a comienzos del siglo XVII», Hispania, LXV/219 (Madrid, 2005b): 67-90.

Álvarez Nogal, Carlos, «L'argent du roi et les hommes d'argent (XVIe-XVIIe siècles)», en Anne Dubet (coord.), Les finances royales dans la monarchie espagnole (XVIe-XIXe siècles), Rennes, Presses Universitaires de Rennes, 2008: 187-198.

Álvarez Nogal, Carlos, Lo Basso, Luca y Marsilio, Claudio, «La rete finanziaria della famiglia Spinola: Spagna, Genova e le fiere dei cambi (1610-1656)», Quaderni storici, 124/1 (Bolonia, 2007): 97-110.

Antunes, Cátia y Polónia, Amélia (coords.), Beyond Empires. Global, Self-Organizing, Cross-Imperial Networks, 1500-1800, Leiden/Boston, Brill, 2016.

Aram, Bethany y Yun Casalilla, Bartolomé (coords.), Global Goods and the Spanish Empire, 1492-1824. Circulation, Resistance and Diversity, Basingstoke, Palgrave Macmillan, 2014.

Barbero, Alessandro, Lepanto. La battaglia dei tre imperi, Bari/Roma, Laterza, 2012 [2010].

Berbouche, Alain, Marine et justice : la justice criminelle de la Marine française sous l'Ancien Régime, Rennes, Presses Universitaires de Rennes, 2010.

Bernabéu Albert, Salvador (coord.), La Nao de China, 1565-1815. Navegación, comercio e intercambios culturales, Sevilla, Universidad de Sevilla, 2013.

Bonialian, Mariano Ardash, El Pacífico hispanoamericano. Política y comercio asiático en el Imperio Español (1680-1784), México, El Colegio de México, 2012.

107 Una discusión reciente de esta literatura en YUN CASALILLA, 2019, especialmente: 323-376.

Hispania, 2020, vol. LXXX, n. ${ }^{\circ}$ 264, enero-abril, págs. 47-77, ISSN: 0018-2141, e-ISSN: 1988-8368

https://doi.org/10.3989/hispania.2020.002 
Braudel, Fernand, La Méditerranée et le monde méditerranéen à l'époque de Philippe II, París, Armand Colin, 1990 [1966].

Brendecke, Arndt, Imperio e información: funciones del saber en el dominio colonial español, Fráncfort, Vervuert, 2012.

Bunes Ibarra, Miguel Ángel de, «La defensa de la cristiandad; las armadas en el Mediterráneo en la edad moderna», Cuadernos de Historia Moderna, V (Madrid, 2006): 77-99.

Carande, Ramón, Carlos Vy sus banqueros, Barcelona, Crítica, 1990 [1943-1967].

Cardim, Pedro, Herzog, Tamar, Ruiz Ibáñez, José Javier y Sabatini, Gaetano (coords.), Polycentric Monarchies. How did Early Modern Spain and Portugal Achieve and Maintain a Global Hegemony?, Brighton/Toronto/Portland, Sussex Academic Press, 2012.

Carlos Morales, Carlos Javier de, El precio del dinero dinástico: endeudamiento y crisis financieras en la España de los Austrias, 1557-1647, Madrid, Banco de España, 2016.

Carpentier, Bastien y Priotti, Jean-Philippe, «Philippe II, Giovanni Andrea Doria et le contrôle militaire de la Méditerranée à la fin du XVIe siècle» en Michel Bertrand y Jean-Philippe Priotti (coords.), Circulations maritimes. L'Espagne et son empire (XVIe-XVIIIe siècle), Rennes, Presses Universitaires de Rennes, 2011: 159-183.

Chaunu, Huguette y Chaunu, Pierre, Séville et l'Atlantique (1504-1650), París, S.E. V.P.E.N., 1955-1960.

Codogno, Ottavio, Nuovo itinerario delle poste per tutto il mondo, Milán, Girolamo Bordoni, 1616.

Codogno, Ottavio, Compendio delle poste, Milán, Gio. Battista Bidelli, 1623.

Crespo Solana, Ana, Mercaderes atlánticos. Redes del comercio flamenco y holandés entre Europa y el Caribe, Córdoba, Universidad de Córdoba, 2009.

Da Silva, José Gentil, Banque et crédit en Italie au XVIIè siècle, París, Klincksieck, 1969.

Elliott, John H., «A Europe of Composite Monarchies», Past and present, 137/1 (Oxford, 1992): 48-71.

Elliott, John H., El conde-duque de Olivares. El político en una época de decadencia, Barcelona, Crítica, 2009 [1986].

Fenicia, Giulio, Il regno di Napoli e la difesa del Mediterraneo nell'età di Filippo II (1556-1598): organizzazione e finanziamento, Bari, Cacucci, 2003.

Fernández Duro, Cesáreo, Viajes regios por mar en el transcurso de quinientos años, Madrid, Tip. Sucesores de Rivadeneyra, 1893.

García García, Bernardo José, La Pax Hispanica. Política exterior del Duque de Lerma, Lovaina, Leuven University Press, 1996.

García Hernán, Enrique, La Armada española en la monarquía de Felipe II y la defensa del Mediterráneo, Madrid, Tempo, 1995.

García-Baquero González, Antonio, La Carrera de Indias: suma de la contratación y océano de negocios, Sevilla, Algaida, 1992.

Gaudin, Guillaume, Penser et gouverner le Nouveau Monde au XVIIe siècle. L'empire de papier de Juan Diez de la Calle, commis du Conseil des Indes, París, L'Harmattan, 2013. 
Gaudin, Guillaume, Castillo Gómez, Antonio, Gómez Gómez, Margarita y Stumpf, Roberta, «Vencer la distancia: Actores y prácticas del gobierno de los imperios español y portugués», Nuevo Mundo Mundos Nuevos [en línea], 2017, disponible en: http://journals.openedition.org/nuevomundo/71453 (consultado el 13 de mayo de 2018).

Gaudin, Guillaume y Valenzuela Márquez, Jaime, «Empires ibériques : de la péninsule au global», Diasporas. Circulations, migrations, histoire, 25 (Toulouse, 2015): $13-24$.

Giráldez, Arturo, The Age of Trade. The Manila Galleons and the Dawn of the Global Economy, Lanham, Rowman \& Littlefield, 2015.

Glete, Jan, Warfare at Sea, 1500-1650. Maritime Conflicts and the Transformation of Europe, Londres, Routledge, 2000.

Grafe, Regina, «On the spatial nature of institutions and the institutional nature of personal networks in the Spanish Atlantic», Culture \& History Digital Journal [en línea], 3/1 (2014), https://doi.org/10.3989/chdj.2014.006.

Gruzinski, Serge, Les quatre parties du monde. Histoire d'une mondialisation, París, Éditions de La Martinière, 2004.

Guilmartin, John Francis, Gunpowder and Galleys. Changing Technology and Mediterranean Warfare at Sea in the Sixteenth Century, Londres, Cambridge University Press, 1974.

Gürkan, Emrah Safa, «The centre and the frontier: Ottoman cooperation with the North African corsairs in the sixteenth century», Turkish Historical Review, 1/2 (Leiden, 2010): 125-163.

Herrero Sánchez, Manuel, «La República de Génova y la Monarquía Hispánica (siglos XVI-XVII)», Hispania, LXV/219 (Madrid, 2005a): 9-20.

Herrero Sánchez, Manuel, «La quiebra del sistema hispano-genovés (1627-1700)», Hispania, LXV/219 (Madrid, 2005b): 115-152.

Herrero Sánchez, Manuel, «Conectores sefarditas en una monarquía policéntrica. El caso Belmonte/Schonenberg en la articulación de las relaciones hispano-neerlandesas durante la segunda mitad del siglo XVII», Hispania, LXXVI/253 (Madrid, 2016): 445-472.

Herrero Sánchez, Manuel, y Kaps, Klemens (coords.), Merchants and Trade Networks in the Atlantic and the Mediterranean, 1550-1800. Connectors of commercial maritime systems, Londres, Routledge, 2017.

Hildesheimer, Françoise, Richelieu, París, Flammarion, 2004.

Kirk, Thomas Allison, Genoa and the Sea: Policy and Power in an Early Modern Maritime Republic, 1559-1684, Baltimore/Londres, Johns Hopkins University Press, 2005.

Ladero Quesada, Miguel Ángel, Ejércitos y armadas de los Reyes Católicos: Nápoles y El Rosellón (1494-1504), Madrid, Real Academia de la Historia, 2010.

Lane, Frederic C., Navires et constructeurs à Venise pendant la Renaissance, París, S.E.V.P.E.N., 1965.

Lang, Mervyn Francis, Las Flotas de la Nueva España (1630-1710). Despacho, azogue, comercio, Sevilla, Muñoz Moya Editor, 1998.

Lercari, Andrea, «Cicala, Visconte», en Dizionario Biografico dei Liguri: dalle origini al 1990, Génova, Consulta Ligure, 1996, vol. III: 417-420.

Hispania, 2020, vol. LXXX, n. ${ }^{\circ}$ 264, enero-abril, págs. 47-77, ISSN: 0018-2141, e-ISSN: 1988-8368

https://doi.org/10.3989/hispania.2020.002 
Lo Basso, Luca, Uomini da remo. Galee e galeotti del Mediterraneo in età moderna, Milán, Selene Edizioni, 2003.

Lo Basso, Luca, «Gli asentisti del re. L'esercizio privato della guerra nelle strategie economiche dei Genovesi (1528-1716)» en Rossella Cancila (coord.), Mediterraneo in armi (secc. XV-XVIII), Palermo, Quaderni Mediterranea, 2007: 397-428.

Lo Basso, Luca, «Una difficile esistenza. Il duca di Tursi, gli asientos di galee e la squadra di Genova tra guerra navale, finanza e intrighi politici (1635-1643)», en Manuel Herrero Sánchez, Yasmina Rocío Ben Yessef Garfia, Carlo Bitossi y Dino Puncuh (coords.), Génova y la Monarquía Hispánica (1528-1713), Génova, Società Ligure di Storia Patria, 2011, vol. II: 819-846.

Lomas Cortés, Manuel, «Las galeras en el aprovisionamiento marítimo de Orán-Mazalquivir (1599-1621)», en Miguel Ángel de Bunes Ibarra y Beatriz Alonso Acero (coords.), Orán. Historia de la Corte Chica, Madrid, Ediciones Polifemo, 2011: 195-221.

Lomas Cortés, Manuel, «Renovar el servicio a la Monarquía tras la muerte del rey: Juan Andrea Doria y el pasaje de la reina Margarita (1598-1599)», en Alicia Esteban Estríngana (coord.), Servir al rey en la Monarquía de los Austrias. Medios, fines y logros del servicio al soberano en los siglos XVI y XVII, Madrid, Sílex, 2012: 193-226.

Maffi, Davide, «Alle origini del "camino español”. I transiti militari in Liguria (15661700)», en Alberto Peano Cavasola (coord.), Finale porto di Fiandra, briglia di Genova, Finale Ligure, Centro Storico del Finale, 2007: 119-149.

Maldavsky, Aliocha, Vocaciones inciertas. Misión y misioneros en la provincia jesuita del Perú en los siglos XVI y XVII, Sevilla, CSIC, 2012.

Maréchaux, Benoît, «Negociar, disuadir y comunicar para la conservación y reputación de la Monarquía: la república de Venecia en las estrategias de la Pax Hispánica bajo el valimiento de Lerma», en Bernardo José García García, Manuel Herrero Sánchez y Alain Hugon (coords.), El arte de la prudencia. La Tregua de los Doce Años en la Europa de los Pacificadores, Madrid, Fundación Carlos de Amberes, 2012: 91-120.

Maréchaux, Benoît, Instituciones navales y finanzas internacionales en el Mediterráneo de la época moderna. Los asentistas de galeras genoveses al servicio de la Monarquía Hispánica (1500-1650), tesis doctoral inédita, Universidad Carlos III de Madrid, 2017.

Marsilio, Claudio, Dove il denaro fa denaro. Gli operatori finanziari genovesi nelle fiere di cambio del XVII secolo, Novi Ligure, Città del silenzio, 2008.

Martínez Ruiz, Enrique, Los soldados del Rey: los ejércitos de la Monarquía Hispánica (1480-1700), Madrid, Actas, 2008.

Mira Caballos, Esteban, «La Armada del Reino de Granada (1492-1550): apuntes para su historia», Revista de historia naval, XVIII/68 (Madrid, 2000): 35-54.

Montañez Matilla, María, El correo en la España de los Austrias, Madrid, CSIC, 1953.

Pacini, Arturo, La Genova di Andrea Doria nell'Impero di Carlo V, Florencia, Leo S. Olschki, 1999.

Pacini, Arturo, «Desde Rosas a Gaeta». La costruzione della rotta spagnola nel Mediterraneo occidentale nel secolo XVI, Milán, Franco Angeli, 2013. 
Pallavicino, Giulio, Inventione di Giulio Pallavicino di scriver tutte le cose accadute alli tempi suoi (1583-1589), ed. de Edoardo Grendi, Génova, Sagep, 1975.

Parker, Geoffrey, The military revolution. Military innovation and the rise of the West, 1500-1800, Cambridge, Cambridge University Press, 1988.

Parker, Geoffrey, La gran estrategia de Felipe II, Madrid, Alianza Editorial, 1998.

Parker, Geoffrey, El ejército de Flandes y el Camino Español 1567-1659. La logística de la victoria y derrota de España en las guerras de los Países Bajos, Madrid, Alianza Editorial, 2006 [1972].

Parrott, David, The Business of War. Military Enterprise and Military Revolution in Early Modern Europe, Cambridge, Cambridge University Press, 2012.

Richelieu, Armand Jean du Plessis, Testament politique, ed. Arnaud Teyssier, París, Perrin, 2011.

Rodger, Nicholas A. M., «From the "military revolution" to the "fiscal-naval state"», Journal for Maritime Research, 13/2 (Londres, 2011): 119-128.

Rodríguez Hernández, Antonio José, España, Flandes y la Guerra de Devolución (1667-1668). Guerra, reclutamiento y movilización para el mantenimiento de los Países Bajos españoles, Madrid, Ministerio de Defensa, 2007.

Rodríguez Hernández, Antonio José, «Reclutamiento y operaciones de enlace y transporte militar entre España y Milán a finales del siglo XVII (1680-1700)», Revista Universitaria de Historia Militar, 5/10 (Zaragoza, 2016): 23-45.

Ruiz Martín, Felipe, Pequeño capitalismo, gran capitalismo. Simón Ruiz y sus negocios en Florencia, Barcelona, Crítica, 1990.

Ruiz Martín, Felipe, «La dispersión de oro y plata por Europa a través del puerto de Barcelona», en Ernest Belenguer Cebrià (coord.), Felipe II y el Mediterráneo, Madrid, Sociedad Estatal para la Conmemoración de los Centenarios de Felipe II y Carlos V, 1999, vol. I: 23-32.

Savelli, Rodolfo, «Doria, Antonio», en Dizionario Biografico degli Italiani, Roma, Istituto della Enciclopedia Italiana, 1992, vol. 41: 280-286.

Schoder, Elisabeth, «Die Reise der Kaiserin Maria nach Spanien (1581/82)», en Friedrich Edelmayer (coord.), Hispania-Austria II. Die Epoche Philipps II (1556-1598) / La época de Felipe II (1556-1598), Viena, Verlag für Geschichte und Politik, 1999: 151-180.

Serrano Mangas, Fernando, Armadas y flotas de la plata (1620-1648), Madrid, Banco de España, 1989.

Sirago, Maria, «I Doria, signori del mare, ed il sistema dell'“asiento" nella costituzione della flotta napoletana all'epoca di Carlo V», en Giuseppe Galasso y Aurelio Musi (coords.), Carlo $V$ e il Mediterraneo, Nápoles, Società Napoletana di Storia Patria, 2001: 665-704.

Sirago, Maria, La flotta napoletana nel contesto mediterraneo (1503-1707), Ogliastro Cilento, Licosia Edizioni, 2018.

Sola Castaño, Emilio, Uchalí. El Calabrés Tiñoso, o el mito del corsario muladí en la frontera, Barcelona, Edicions Bellaterra, 2010.

Studnicki-Gizbert, Daviken, A Nation upon the Ocean Sea. Portugal's Atlantic Diaspora and the Crisis of the Spanish Empire, 1492-1640, Oxford, Oxford University Press, 2007. 
Subrahmanyam, Sanjay, «Holding the World in Balance: The Connected Histories of the Iberian Overseas Empires, 1500-1640», The American Historical Review, CXII/5 (Chicago, 2007): 1359-1385.

Thompson, Irving A. A., War and Government in Habsburg Spain 1560-1620, Londres, The Athlone Press, 1976.

Thompson, Irving A. A., «Aspectos de la organización naval y militar durante el Ministerio de Olivares», en John H. Elliott y Ángel García Sanz (coords.), La España del Conde Duque de Olivares, Valladolid, Universidad de Valladolid, 1990: 249-274.

Thompson, Irving A. A., «Las galeras en la política militar española en el Mediterráneo durante el siglo XVI», Manuscrits, 24 (Barcelona, 2006): 95-124.

Vargas Hidalgo, Rafael, Guerra y diplomacia en el Mediterráneo. Correspondencia inédita de Felipe II con Andrea Doria y Juan Andrea Doria, Madrid, Polifemo, 2002.

Williams, Phillip, «Past and present: the forms and limits of Spanish naval power in the Mediterranean, 1590-1620», en Mario Rizzo, José Javier Ruiz Ibáñez y Gaetano Sabatini (coords.), Le forze del Principe. Recursos, instrumentos y límites en la práctica del poder soberano en los territorios de la Monarquía Hispánica, Murcia, Universidad de Murcia, 2003, vol. I: 237-278.

Williams, Phillip, Empire and Holy War in the Mediterranean. The Galley and Maritime Conflict between the Habsburgs and Ottomans, Londres/Nueva York, I.B. Tauris, 2014.

Yun Casalilla, Bartolomé (coord.), Las redes del Imperio. Élites sociales en la articulación de la Monarquía Hispánica, 1492-1714, Madrid, Marcial Pons, 2009.

Yun Casalilla, Bartolomé, Iberian World Empires and the Globalization of Europe 1415-1668, Singapur, Palgrave Macmillan, 2019.

Recibido: 06/07/2018

Aceptado: 12/08/2019 